\title{
COREOGRAFIAS DO PODER
}

\begin{abstract}
Alberto Amaral ${ }^{1}$
Lilian Lobato ${ }^{2}$

Resumo: Este trabalho pretende discutir as formas de resistência presentes nos filmes Quase dois irmãos, de Lucia Murat, Valentin, de Alejandro Agresti, e no curta-metragem Baseado em estórias reais, de Gustavo Moraes, a partir dos conflitos originados no choque dos discursos em relações de poder dentro de um Estado de Exceção ou mesmo em âmbito familiar. Compreendendo que todo discurso é uma prática de poder - saber entre os sujeitos. Para tal compreensão buscamos as elucidações do filosofo francês Michel Foucault, o qual desenvolveu suas idéias em torno do poder a partir de sua segunda fase de pensamento, conhecida como momento genealógico, especificamente o poder opressor exercido durante as ditaduras militares do Brasil e da Argentina, confronta-se com outros opositores e presentes no mesmo âmbito social, seja por meio do cárcere, seja por meio da relação de autoridade entre pai e filho.
\end{abstract}

Palavras chave: Discurso, resistência, poder-saber, stigma, ditadura.

Abstract: This work intends to discuss the kinds of resistance presented on the films Quase dois irmãos, by Lucia Murat, and Valentin, by Gustavo Moraes, from the conflicts origined in the confrontation of speeches in power relationship within a State of Exception, or even in familiar environment. From the understanding that every speech is some practice of power - knowledge among the subjects. For such understanding we have sought the elucidating ideas made by the French philosopher Michel Foucault, who developed them regarding power in his second phase of thinking known as the genealogical phase, especifically the oppressive power carried out during Brazil's and Argentina's military dictatorship, confronted with other oppositors and present in the same social sphere, either by the means of imprisonment, or by the relationship of authority between a parent and his/her child.

Keywords: Speech, resistance, power-knowledge, stigma, dictatorship.

Em toda parte se está em luta.

(FOCAULT, 2003.p. 232)

\footnotetext{
${ }^{1}$ Mestre em Psicologia Social pela UFPA. Professor da Escola Superior Madre Celeste (ESMAC). Pesquisador do grupo Narrativas de Resistência. Pesquisador do Núcleo Interdisciplinar Kairós, participando do projeto de pesquisa "A obra de arte na ética das Questões”, coordenado pelo professor Dr. Antonio Máximo Ferraz. E-mail. albertoamaral@gmail.com.

${ }^{2}$ Mestranda do Programa de Pós-Graduação em Letras da UFPA. Bolsista CAPES. e-mail: lilianlobato3@gmail.com
} 


\section{INTRODUÇÃO}

Comecemos pelo título: este texto procura refletir criticamente a construção fílmica do conflito entre os discursos do poder e da resistência a partir das observações feitas nos filmes Quase dois irmãos, de 2004, da diretora Lucia Murat, do curta-metragem Baseado em estórias reais, lançado em 2002, sob a direção de Gustavo Moraes, e Valentin, sob a direção de Alejandro Agresti, lançado também em 2002. A partir das observações feitas nos filmes Quase dois irmãos e Baseado em estórias reais, pretendemos observar os jogos discursivos presentes, tanto nos conflitos de discursos entre duas realidades sociais distintas, quanto entre o poder do Estado durante o regime militar e os cidadãos que não concordavam com a falta de liberdade de expressão dentro de seu próprio país. Paralelamente, observaremos, em Valentin, a criação de uma criança que, para fugir ou mesmo modificar sua própria realidade a fim de obter a realização de seus sonhos, como o de ter uma família tradicional e sólida, é capaz de recriar, por meio de suas brincadeiras e incursões pelas artes, em especial a narrativa, sua própria vida, resistindo, assim, a todo um quadro de opressão, tanto hierárquico dentro do âmbito familiar, quanto político, durante o regime ditatorial argentino.

Em seguida, realizaremos um debate em torno dos jogos do poder discursivo, tendo como eixo de referência a filosofia analítica do poder elaborada por Michel Foucault. Neste problema, observa-se que esses jogos são elaborados como consequência dos conflitos sociais, inicialmente desenvolvidos nos filmes, impostos pelo Estado totalitário. Em seguida, percebemos que o resultado do confronto destes discursos manifesta-se socialmente pelo medo, fruto da violência urbana, uma resultante das forças globais exercidas pela nova política global. Isto pode ser visto no filme Quase dois irmãos quando Miguel (Caco Ciocler) proíbe a filha de namorar um traficante. Isso ele o faz após conviver, na prisão de Ilha Bela, com pessoas de classe social diferente da sua e ter todas as suas convicções sócio-políticas de socialismo e igualdade confrontadas com outro discurso, o dos excluídos, no qual prevalece, sobre qualquer princípio moral ou ético, o de sobrevivência. Já em Valentin, o discurso da personagem é diferente, pois o filme retrata a realidade de um garoto que tenta fugir da realidade imprimida pelo Estado Totalitário da época e pelas relações de autoridade estabelecidas em âmbito familiar, criando seus próprios mecanismos de resistência em suas brincadeiras, como será visto posteriormente.

Sabendo que o projeto foucaultiano - enunciado, por exemplo, em "Verdade e poder" (1979), parte da problematização do sujeito, é que visamos chegar a uma análise que pudesse dar conta da constituição do mesmo, em que tomamos como base a trama histórica, de forma a livrar o indivíduo constituinte da experiência humana e universal em sua substância. Esta noção perpassa por toda a episteme moderna que atua como determinante das práticas ocidentais contemporâneas é retratada nas películas, Foucault (1995) propõe que entender a transformação dos seres humanos em sujeitos é uma forma de luta contra as sujeições e os aspectos fundamentais destas é o de questionar o estatuto do indivíduo.

Para a realização desta análise das relações de poder, as quais chamamos, neste trabalho, de "Coreografias de Poder", apresentaremos três questões relacionadas às películas de forma a compreender como Foucault discorre sua teoria do poder e onde propõe uma 
analítica do mesmo, entendendo-o a partir de outros aspectos que não os tradicionalmente postos a fim de pensarmos uma série de modelos anteriores.

É preciso pensar que o Poder também produz realidades, conhecimentos, modos de ser. Inclusive o indivíduo e o conhecimento que se pode ter sobre ele se dão nessa produção (Foucault, 1987). Nas palavras do autor: "O que faz com que o poder se mantenha e que seja aceito é simplesmente que ele não pesa só como a força que diz não, induz ao prazer, forma saber, produz discurso" (Foucault, 1979, p. 8).

Um segundo ponto importante para uma analítica do poder é o abandono do modelo legal. Foucault diz ser da imagem jurídica e discursiva, tradicionalmente atribuída ao poder, que "precisamos liberar-nos, isto é, do privilégio teórico da lei e da soberania, se quisermos fazer uma análise do poder nos meandros concretos e históricos de seus procedimentos" (Foucault, 1988, p. 100).

Afastando-se do modelo legal, pode-se ter uma nova percepção do poder: ele não é algo do qual se tenha propriedade, que se adquira ou compartilhe. Não há como considerar, nessa perspectiva, uma oposição entre "dominantes" e "dominados", onde os primeiros tenham conquistado o poder a ponto de colocar os "dominados em uma relação de exterioridade a esse processo”. Ao contrário, as relações de poder presumem um enfretamento perpétuo.

Temos, em suma que adquirir que esse poder se exerce mais do que se possui, que não é privilegio adquirido ou conservado da classe dominante, mas o efeito conjunto de suas posições estratégicas - efeito manifestado e às vezes reconduzido pela posição dos que são dominados. (FOUCAULT, 1987. p. 29)

Nesse sentido, Foucault (1979) sugere que se considere outro modelo para a inteligibilidade das relações de poder: o modelo da guerra. Suas táticas e estratégias devem ser entendidas em termos de confronto e de controle, onde se tem "por princípio cumular vantagens e multiplicar benefícios” (Foucault apud Maia, 1995, p. 91). É dessa maneira que a extensa rede de poder se desdobra, articula-se e atravessa todo o corpo social.

O que parece certo para a análise de poder é a existência de dois modelos: o proposto pelo Direito (poder como lei, proibição, instituição) e o modelo guerreiro ou estratégico em termos de relações de forças. (Foucault, 1979, p. 241).

\section{AS RELAÇÕES DE PODER NAS PERSONAGENS}

Percebendo que essas relações de poder existentes entre os principais personagens do filme "Quase dois irmãos" vemos, a partir das lembranças provocadas pelo reencontro entre Miguel (Caco Ciocler), deputado federal e Jorge (Flavio Bauraqui), líder do Comando Vermelho. A história dos dois começa quando ainda são crianças e brincavam na favela enquanto o pai de Miguel, homem de classe média, compunha com o pai de Jorge, sambista. A convivência pacífica entre eles criou nestes meninos a esperança do fim da desigualdade social e do racismo.

Já adulto Miguel, torna-se preso político no cárcere de Ilha Bela. O ano é 1970. Período 
auge da ditadura militar. Nessa mesma época também foram mandados para esta prisão criminosos comuns. Entre eles está Jorge. O choque entre realidades instaura-se e, dessa convivência, desfaz-se o sonho de uma sociedade igualitária e pode-se ver o surgimento do poder paralelo do narcotráfico, com a criação do Comando Vermelho. Comando este pensado a partir das observações sobre comportamento dos presos políticos pelos presos comuns, como seu sistema de parceria para fugas, o regime comunal da facção dentro do presídio, a escolha da cor para simbolizá-lo e o lema entre seus membros: "Paz, justiça e igualdade".

Dentro dessa realidade percebemos que os discursos produzidos entre os personagens criaram uma linguagem própria, um código dentro de cada realidade vivida pelo os mesmos, o que nos permitiu falar sobre, de tal forma, que a tornou um vazio, funcionando como um ruído. Como enfatiza Foucault (1979). As vidas de Jorge e Miguel se cruzam em três momentos: durante a infância com os pais; na fase adulta, dentro de Ilha Bela e na maturidade, quando cada um destes já vive de acordo com sua realidade social. Esse último reencontro ocorre devido o relacionamento amoroso da filha de Miguel (Maria Flor) com um dos traficantes de Jorginho, onde ressurge a discussão sobre a possibilidade de convivência entre pessoas de realidades distintas.

Os discursos são elementos ou blocos táticos no campo das correlações de forças. Dessa maneira as descontinuidades sugerem a indagação e torna-se necessário admitir que exista um jogo complexo e instável, no qual o discurso pode reforçar o dito como também pode causar resistências, como mostra o excerto:

como é possível que se tenha em certos momentos e em certa ordem de saber, estas mudanças bruscas, estas precipitações de evolução, estas transformações que não correspondem à imagem tranqüila que normalmente se faz? (Foucault, 1979, p. 104)

Notemos que durante a prisão, fato esse ocorrido tanto em Quase dois irmãos quanto em Baseado em estórias reais, filmes onde os estigmas sociais evidenciam-se em virtude do confinamento, produzindo complexas e plurais identidades. Estas, contudo, deterioram-se em virtude da privação de liberdade e da própria violência física sofrida no cárcere, como a tortura mostrada em Baseado em estórias reais; tornam-se, em determinado momento, "o objeto da intolerância coletiva, além de estarem carregados de estigmas, como o da condição de desacreditados" (Goffman, 1988, p. 14).

\section{COMO OS DISCURSOS PASSAM A SER VISTOS}

Nesse sentido, todas as ações, discursos e posturas passam a ser vistos como anormais desviantes - sujeitos à ação judiciária, à intervenção médica. Atentos e teoricamente examinados tornando um problema social. Em Quase dois irmãos vemos a força do estigma social, na primeira noite de Jorge em Ilha Bela. Ele, por ser preso, comum e negro fora violentamente espancado pelos guardas da prisão, o que não acontecia com os presos políticos, homens instruídos e conscientes de seus direitos enquanto prisioneiros. Já em Baseado em 
estórias reais, vemos a violência e a intolerância durante a tortura realizada por um policial em um militante, que também sabia de seus direitos enquanto detento, mas tinha consciência da violência empregada pelo Estado para reprimir qualquer movimento de resistência. Sua morte, pois este personagem, no qual em uma tentativa frustrada de assalto a banco, é preso e violentamente torturado, já estava prevista, afinal em Estado totalitário, pessoas que decidem combater o sistema vigente em função de suas convicções políticas por meio de atos de transgressão social (como as guerrilhas e a militância) são, fatalmente, punidos de modo violento para servir de exemplo à sociedade.

Em Baseado em estórias reais, temos histórias a confundir-se: a primeira é a de um preso político a responder criminalmente a duas acusações: uma tentativa de assalto e outra, falsa, a de ter atirado em uma idosa durante este roubo fracassado (fato que ocorre, mas feito pelo policial que prende o militante e tortura-o em seguida). Estes dois fatos seriam tratados, como já foi dito, a partir de um problema social não fosse a intervenção de uma jornalista presente no banco durante o momento da prisão. Afinal, nos tempos de chumbo, todos os sujeitos que se colocavam contra a ordem eram subversivos ou até mesmo criminosos e não mereciam, portanto, sequer ter seu corpo devolvido para a família.

É o que quase ocorre em Baseado em estórias reais, não fosse o cruzamento da estória de uma jornalista que estava presente no momento do assalto. Para que sua vida pudesse se cruzar com a deste jovem a mesma encontra, no chão do banco após a ação policial, o documento de identificação do preso político após este ser levado. A vontade de descobrir até onde iria a violência da repressão ditatorial, levou-a a iniciar uma investigação minuciosa sobre a ação dos policiais durante esta ação em específico, como uma forma, também de não tornar vã a morte deste rapaz. Ao final de sua investigação, a jornalista possui uma longa e detalhada matéria, a denunciar toda a barbárie provocada pela ditadura militar.

Essa matéria, contudo, não chega a ser publicada, pois a vida da jornalista cruzasse com a do censor de seu jornal, o mesmo homem que havia torturado o rapaz pelo qual ela escrevia a matéria. Ele proíbe a publicação e, em seu lugar a faz publicar uma receita de bolo. A jornalista o faz, e assim é publicado o "Bolo Independência. Este bolo, que fora passado ao leitor com os ingredientes errados, possibilita o surgimento de mais uma personagem: uma dona-de-casa, que vive de alienada a todo o quadro político brasileiro, decide preparar a receita para esperar o retorno do filho. Mas esse filho não volta, pois era o militante do assalto ao banco. O filme "Quase dois irmãos", também nos mostra a forma na qual o Estado reprimia, dentro do cárcere, os chamados "subversivos" ao confinar no mesmo recinto presos políticos e presos comuns, afinal crime é crime, e todos devem ser punidos pelo mesmo vigor da lei.

A interdição e a mutação são os mecanismos mais frequentes que se enquadram a esses sujeitos. A forma mais comum, superficial e visível desses sistemas complexos de restrição é a normatização, sobretudo para os sujeitos considerados desviantes dela. Logo "o poder está em toda parte; não porque englobe tudo e sim porque provém de todos os lugares" (Foucault, 1988. p. 89). Este, portanto, encontra-se presente nas microrrelações do cotidiano institucional, seja entre os presos políticos, ou seja, entre os presos comuns e o corpo institucional. Assim 
Pode-se mesmo dizer que, na maioria dos casos, os mecanismos disciplinares de poder e, os mecanismos disciplinares do corpo e os mecanismos reguladores da população, são articulados um com o outro. (FOUCAULT, 1999, p. 299)

Nesse momento, vale situar que essas formas de privações exercidas pelo Estado sobre os presos políticos, mostradas em Quase dois irmãos e Baseado em estórias reais, eram formas de punição onde os sujeitos não tinham nenhum direito sobre seu próprio corpo, muitas vezes eram vítimas de diversas formas de torturas e da mesma forma assim o eram os presos comuns. No entanto, durante a convivência entre os personagens Miguel e Jorginho, esses jogos de poder mudam de sentindo. De um lado há o político de Miguel, socialista, de classe média alta, com ensino completo. Do outro há o discurso de Jorge, negro, até aquele momento um pequeno assaltante, sem ensino completo, vindo da favela. Jorge, ao chegar, recebe uma série de ordens pré-estabelecidas pelo "coletivo" de presos políticos, todos da mesma classe social de Miguel. Sobre essa aceitação de Jorge às regras do amigo, mostra-nos Gregolin a partir de seus estudos em Michel Foucault em especial a sua primeira fase, a arqueológica:

[...], pode-se perceber que Foucault está interessado, ao propor uma arqueologia do saber, em analisar as condições de possibilidade de discursos, o campo problemático que lhes assinala um certo modo de existência e que faz com que, em determinada época, em determinado lugar, não se diga, não se diga absolutamente qualquer coisa. (GREGOLIN, 2003, p. 12)

\section{COMO PENSAR A RELAÇÃO DE PODER}

Pensar as relações de poder como um modo de "ação sobre ações" significa dizer que seu exercício consiste em "conduzir condutas", o que o caracteriza como "governo" de uns pelos outros. Não o "governo" restrito às estruturas políticas e à gestão dos Estados, como já dissemos, mas no sentido amplo que tinha no século XVI, no qual qualquer um podia exercer poder sobre outros, bastando para isso que uma pessoa ou um grupo de pessoas se permitisse ser guiado em suas condutas.

No entanto o silêncio, o conformismo de Jorge no filme Quase dois irmãos, dura até a chegada de mais presos comuns. Pessoas que compartilhavam de sua visão de mundo. Todos viventes de sua mesma realidade social. A partir desse momento começa um embate direto entre os ideais de justiça e igualdade entre os que tiveram estudos e estavam presos por sonhar com a construção de uma sociedade mais justa, igualitária, sem distinção de classes e os que não tiveram formação escolar completa, viviam em morros onde os serviços básicos estatais não os atendiam, além de conviverem com a violência e o crime.

Estes presos tinham, contudo, sua própria lógica social e Jorge tenta apresentar a Miguel seu discurso sobre vivência em sociedade, que ia desde reações pequenas, como dizer palavras de baixo calão para a foto da namorada infiel do amigo, a outras maiores, como o assassinato de toda a facção rival à de Jorge, pois esta não aceitava as ordens do "coletivo" de Miguel. Matando-os, Jorge supunha tornar extinta a separação entre a ala de presos políticos 
e a de comuns, materializada pela construção de um muro a separar presos comuns de presos políticos. Todavia, Jorge conseguiu, a contrário de sua expectativa, afastar-se definitivamente do amigo, reencontrando-o muito tempo depois ao cárcere.

Estes fatos mostram a dificuldade em se aceitar o discurso do outro, compreendê-lo, pois o de Miguel e de seus amigos era o de homens instruídos, que em sociedade ocupa uma posição de prestígio em detrimento ao de Jorge, pois este não possuía uma formação acadêmica e, portanto, não teria um saber interessante para ser compartilhado. O pensamento de Jorge, no caso, não era interessante para uma prisão de presos políticos, pois eles eram os reais detentores de conhecimento aceito socialmente. Sobre isso, Foucault afirma (1996, p. 17):

Em uma sociedade como a nossa conhecemos, é certo, procedimentos de exclusão. O mais evidente, o mais familiar também, é a interdição. Sabe-se bem que não se tem o direito de dizer tudo, que não se pode falar de tudo, que não se pode falar de tudo em qualquer circunstância, que qualquer um, enfim, não pode falar de qualquer coisa.

Dessa forma, o cotidiano que podemos observar de nossa sociedade, perpassa por uma rede de conexões que se ligam às relações de poder entre os sujeitos. Percebendo que os jogos de poder e as punições estão sofisticados, não há um deliberado ato de punição contra o corpo com a frequência que se tinha antes. O que há são ações punitivas de caráter mais intenso contra os sujeitos, de uma forma maior a atingir suas subjetividades e sua construção enquanto individuo. Nesse constante jogo, com a entrada em cena das forças, dispositivos de poder são articulados com as estratégias que normalmente são provenientes das autoridades e das normas. Aqui o conceito de estratégias é apropriado de Michel de Certeau (1994), o qual chama de estratégia:

O calculo ou a manifestação das relações de forças que se torna possível a partir do momento em que um sujeito de querer e poder [uma empresa, um exercito, uma cidade, uma instituição cientifica] pode ser insolado. A estratégia postula um lugar suscetível de ser circunscrito como algo próprio a ser base de onde se podem gerir as relações com uma exterioridade de alvos ou ameaças [...]. Gesto cartesiano, quem sabe: circunscrever um próprio num mundo enfeitiçado pelos poderes invisíveis ao Outro. Gesto da modernidade cientifica, politica ou militar. (CERTEAU, 1994, p. 99)

Percebemos que novas tecnologias de poder na constituição do sujeito vão se formando, tanto em Miguel, que assume posturas contrárias a suas antigas convicções, como as de Jorge, quando este deixa de acreditar no sonho de igualdade proporcionado durante a infância pelo samba, para tornar-se líder de uma facção criminosa, Segundo Dreyfus e Rabinow (1995), o poder no regime disciplinar não somente individualiza a partir das observações constantes que dirige a cada um que busca gerir, como fixa a individualidade no campo da escrita. Para os autores: 
Um vasto e meticuloso aparelho documental torna-se componente essencial para o crescimento do poder. Os dossiês capacitam as autoridades a fixar uma rede objetiva de codificação. [...] O indivíduo moderno - objetivado, analisado e fixado - é uma realização histórica. O poder não aplica seu saber, suas investigações, suas técnicas ao universal, mas ao indivíduo como objeto e efeito de um entrecruzamento do poder e do saber. (DREYFUS \& RABINOW, 1995, p. 176)

Para a constituição de sujeitos normalizados, instauram-se "micropenalidades" em relação ao tempo, às atividades, ao modo de ser, ao corpo etc., em que pequenos desvios devem ser penalizados. Esse sistema funciona como um pequeno mecanismo penal a sancionar ou gratificar as ações dos sujeitos com finalidade de normaliza-los. Separam-se a partir dele os "bons" dos "maus", categorizando como "anormais" aqueles que não se assujeitam e são sancionados, já que resistem à norma, mesmo privados de liberdade. Sua função primordial é a correção a partir de um método punitivo ou, antes, a redução dos desvios, dos erros pela ameaça da punição. Este mecanismo implica

a qualificação dos comportamentos e dos desempenhos a partir de dois valores opostos do bem e do mal; em vez da simples separação do proibido, como é feito pela justiça penal, temos uma distribuição entre pólo positivo e pólo negativo. [...] Uma contabilidade penal, constantemente posta em dia, permite obter o balanço positivo de cada um. (FOUCAULT, 1987, p. 161)

Foucault (2008) esclarece que a disciplina estabelece um modelo construído em função de determinados resultados e quem consegue ser enquadrado ou se enquadrar nele é considerado "normal", "cidadão", "gente do bem". Faz-se assim a separação daqueles que não conseguem tal feito e, portanto, são considerados "anormais", "incompetentes", "antissociais", "não humanos".

\section{CONCLUSÃO}

A constituição do "sujeito infrator" se dá, portanto, concomitantemente à produção do "sujeito disciplinar". Jorginho era constituído na prisão como infrator, não somente em virtude do ato cometido, mas especialmente pela conduta resistente ao processo de assujeitamento imposto pelo rol de normas a serem seguidas para ser considerado "normal". Diferente de Miguel, que estava ali para ser punido por pensar diferente, ter outra concepção ideológica que em conflito com a do Estado. Porém, muda de postura ao perceber que a dança do poder estava de outro modo.

Tudo isso demonstra que as punições tanto exercidas pelo Estado quanto pelas novas formas de poder, como no filme de Lucia Murat, mostra-nos a formação de uma nova força em nossa sociedade, na qual se cria um medo social visto e sofrido por todos atualmente. Ela está em função dessa complexa engenharia criminosa, perpassada por uma série de mecanismos produzidos em torno do poder. Dentro de um espaço como a nossa sociedade 
contemporânea, como escapar às capturas das estratégias de punições? Como resistir a essa tecnologia disciplinadora?

Paralelamente aos filmes de Lucia Murat e Gustavo Moraes, temos a película argentina, Valentin (2002), na qual temos contra a violência, uma resistência manifestada de forma implícita. Ela surge, como denomina Alfredo Bosi (2002), sob uma forma imanente. Elas estão presentes ao observarmos a vida de Valentin (Rodrigo Noya), uma criança de nove anos em seu quotidiano familiar na Argentina no ano de 1970, período inicial da ditadura militar no país. Trata-se de uma criança sonhadora a viver com a avó viúva e o pai. Este vive em função do trabalho e tem poucos momentos com o filho. Também há um tio escritor que, por motivos não explicitados na película, passa muito tempo viajando. Sua mãe, por sua vez, desaparecera desde a separação conjugal.

Valentin cresce, portanto, muito solitário, a ouvir as histórias de sua avó, além de criar suas próprias. Seus sonhos eram conhecer sua mãe, tornar-se um astronauta e ter uma família aceitável para os padrões sociais. Apesar da solidão e da instabilidade familiar, ele é uma criança criativa e busca, por meio de sua imaginação e suas brincadeiras, adequar-se a sua realidade. Surge nesse momento, portanto, a visão da criança e a incompreensão do adulto sob a mesma, pois estes não são capazes de compreender a lógica do garoto e suas necessidades, como a fuga de seu próprio mundo contida na sonhada realização profissional e a criação de sua "família dos sonhos", ao unir a antiga namorada de seu pai com seu vizinho, seu amigo pianista. Assim o menino projetaria nessa união sua futura felicidade ao "ter" uma família comum e estável, com pais unidos, presentes e carinhosos. Para o plano dos adultos aquilo nada mais é do que uma brincadeira infantil, mas para o menino trata-se de sua própria forma de resistir em meio às instabilidades, tanto familiares quanto sociais. Sobre o conhecimento da criança, mostra-nos Vânia Maria Resende:

Mesmo o adulto dispondo de um notável conhecimento científico da realidade da mente infantil e do comportamento da criança, é difícil ou mesmo impossível supor uma relação de perfeita compreensão entre os planos adulto e infantil. Nos limites teóricos é admissível o domínio de uma sabedoria sobre o mundo da criança, mas dizer que o adulto vive em total harmonia com ele e que dele participa de igual para igual é estar próximo ou nos limites mesmo da utopia, porque a percepção adulta, filtrada pelo racionalismo, tolera com mais agrado e segurança o lado lógico e unidirecional das coisas; se a opção não for essa, o homem tem que assumir o risco de perder a diretiva linear do mundo, transportando-se ao nível das fantasias, dando margem àquele terreno do inconsciente e do irracionalismo, que ele procura controlar, abafar, ou do qual procura desviar-se através de racionalizações conscientes ou não. (RESENDE, 1988, p. 170)

Em Valentin, como fora dito, a resistência surge de forma imanente, segundo Alfredo Bosi (2002). De acordo com o autor, esta significa opor-se, estar em desacordo com determinada situação. Oferecer obstáculos à aceitação de algo. Logo, envolve uma série de conceitos sociais, como a moral e a ética, entre o julgar correto ou inadequado. Já a narrativa é uma manifestação ligada à harmonia, não precisa estar de acordo com a realidade. Logo 
a narrativa, como manifestação artística, não deveria ter relação com princípios éticos de uma determinada cultura. Entretanto, a literatura consegue estabelecer esse vínculo entre realidade e ficção. Como mostra Bosi (2002), esta pode apresentar a resistência sob a forma de tema ou sob uma forma intrínseca à escrita de uma obra, não sendo, portanto, seu foco, mas algo que o subjaz.

Na película a resistência manifesta-se sob a forma de uma criança que, por meio do jogo e da arte (a música e a literatura), encontra uma fuga de sua realidade e constrói outra em suas brincadeiras. Valentin, como narrador de sua própria história, conta-nos por elas a forma pela qual conseguira superar o divórcio dos pais, o desaparecimento da mãe e a ausência paterna, a doença e morte da avó, a desconstrução de pré-conceitos erigidos a partir do pensamento do pai anti-semita quando o menino torna-se amigo de um pianista judeu, seu vizinho, bem como o período de repressão militar argentino. O garoto, que durante os momentos de crise familiar, brincava com sua roupa de astronauta, ao final da trama muda, desiste de viajar para o espaço, de buscar uma fuga física de seu próprio mundo. Para superar a solidão passa a visitar seu vizinho e a ouvir música, ou então escrever. Valentin deseja, ao final, tornar-se escritor e não mais fugir, mas resistir e manifestar nos textos seus sonhos, suas idealizações. Como afirma-nos Alfredo Bosi:

Chega um momento em que a tensão $\mathrm{eu} /$ mundo se exprime mediante uma perspectiva crítica, imanente à escrita, o que torna o romance não mais uma variante literária da rotina social, mas o seu avesso; logo, o oposto do discurso ideológico do homem médio. (...). A vida como objeto de busca e construção, não a vida como encadeamento de tempos vazios e inertes. (...). A escrita da resistência, a narrativa atravessada pela tensão crítica, mostra, sem retórica nem alarde ideológico, que essa "vida como ela é" é, quase sempre, o ramerrão de um mecanismo alienante, precisamente o contrário da vida plena e digna de ser vivida. (BOSI, 2002, p. 130)

Percebe-se, em Valentin, um uso proposital de uma criança para ser a personagem central com o intuito de possibilitar ao leitor a visão diferenciada do mundo, a que só um garoto pode ter. A amizade do garoto com o pianista é fundamental tanto para a quebra de preconceitos mantidos pelo pai e avó do menino quanto para apresenta-lo às artes. Estas, no filme, ajudam-no a repensar sobre sua própria vida, recria-la a partir do momento em que é usada como atividade lúdica, sendo motivada pela intuição amorosa ao conhecer a mais nova namorada do pai, Leticia (Julieta Cardinali). Também o ajudam a recuperar a crença de que tudo pode encontrar uma renovação por meio da arte, inclusive formar sua própria família a partir da união amorosa de seus novos amigos.

Portanto em Valentin, Quase dois irmãos e Baseado em estórias reais, vemos formas diferenciadas de resistência, presentes tanto na luta consciente contra um sistema autoritário, imposto pelos dispositivos de poder instituídos socialmente, quanto a inconsciente, contrária à autoridade paterna, da qual apenas instituía-se enquanto nome, mas não dava conta de suas outras obrigações afetivas com o menino, assim como o Estado ao punir violentamente quem se opunha a suas regras, mas sem ofertar ao cidadão uma sociedade 
justa, sem oportunidades igualitárias e sem, durante a repressão, liberdade para exprimir sua opinião.

\section{REFERÊNCIAS}

BOSI, Alfredo. Literatura e Resistência. São Paulo: Companhia das Letras, 2002.

CERTEAU. Michel de. Fazer com: usos e táticas. In: A invenção do cotidiano: 1- Artes de

Fazer. Petrópolis, Rio de Janeiro: Vozes, 1994.

FOUCAULT, Michel. A ordem do discurso. 9. ed. São Paulo: Loyola. $1996 \mathrm{~b}$.

A verdade e as formas jurídicas. Rio de Janeiro: Nau Editora, 1999.

A vida dos homens infames. In: Motta, M. B. da (Org.). Estratégia, poder saber. 2. ed. Rio de Janeiro: Forense Universitária, 2006. Vol. IV (Coleção Ditos \& Escritos)

Arqueologia do saber. Rio de Janeiro: Forense-Universitária, 2005.

. Em defesa da sociedade. Curso no Collège de France (1975-1976). São Paulo: Martins Fontes, 2002.

Microfísica do poder. 24. ed. Rio de Janeiro: Edições Graal, 1979.

“Omnes et singulatim: uma Crítica da Razão Política”. In: MOTTA, M. B. da. (Org.)

Estratégia poder-saber. 2. ed. Rio de Janeiro: Forense Universitária, 2006b, p. 355-385. Vol. IV. (Coleção Ditos \& Escritos)

O sujeito e o poder. In: DREYFUS, H. \& RABINOW, P. Michel Foucault, uma trajetória filosófica: para além do estruturalismo e da hermenêutica. Tradução de Vera Porto Carrero. Rio de Janeiro: Forense Universitária, 1995.

Os anormais. Curso no Collège de France (1974-1975). São Paulo: Martins Fontes, 2001.

Segurança, Território, População. Curso no Collège de France (1977- 1978). São Paulo: Martins Fontes, 2008.

Vigiar e punir: história da violência nas prisões. 9. ed. Petrópolis: Vozes, 1987.

GOFFMAN. Erving. Estigmas: notas sobre a manipulação das identidades deterioradas. Rio de Janeiro, Zahar editores, 1998. 
GREGOLIN, Maria do Rosário Valencise. Análise do Discurso: Lugar de enfrentamentos teóricos. In: FERNANDES, C.; SANTOS, J.B. (Org.). Teorias Linguísticas: problemáticas contemporâneas. Uberlândia: UFU, 2003.

Manicômios, prisões e conventos. São Paulo: Perspectiva, 2003.

MAIA, A. C. Sobre a analítica do poder de Foucault. Tempo Social; Rev. sociol. USP, São Paulo, n. 7 (1-2), p. 83-103, out. 1995.

RESENDE, Vânia Maria. O menino na literatura brasileira. São Paulo: Editora Nova Perspectiva, 1988.

\section{FILMOGRAFIA}

BASEADO em estórias reais. Direção de Gustavo Moraes. Produção de Ana Murta e Vanessa Frisso. Vitória: LCA Produções, 2002. 1 DVD (15 min), Cores. Son.

QUASE dois irmãos. Direção de Lucia Murat. Produção de René Bittencourt. Rio de Janeiro: Taiga Filmes e Vídeo, 2004. 1 DVD (102 min), Cores, Son.

VALENTIN. Direção de Alejandro Agresti. Argentina, 2002. 1 DVD (86 min), Cores. Son. 